\section{Author Reply: Decision-Making Management of Women with a High Risk of Developing Breast and Ovarian Cancer}

\section{To the Editor:}

With great attention we read the letter from Briasoulis et al. and appreciate the opportunity to reply to it.

We agree with Briasoulis et al. that decision-making management of women with a highly increased risk of developing breast and ovarian cancer is very complex. However, compared with other options to reduce the risk of developing breast cancer (BC), including prophylactic bilateral salpingo-oophorectomy (PBSO) and surveillance, prophylactic mastectomy $(\mathrm{PM})$ remains the most effective preventive intervention at this moment. Both our present study as well as the prospective study by Meijers-Heijboer et al. ${ }^{1}$ showed no breast cancer occurrence after PM in unaffected high-risk women. This indicates a risk reduction of developing breast cancer of at least $90 \%$, while other preventive options result in a risk reduction of approximately $50 \%$ at the most. Although these data are not available yet, it is expected that PM ultimately will result in a significant mortality reduction in this group after longer follow-up, which is the ultimate goal. Regarding the group of women with a history of breast cancer undergoing PM, neither contralateral breast cancer nor local recurrence occurred after bilateral or contralateral PM. These data are reassuring in view of the fact that $\mathrm{BRCA} 1 / 2$ mutation carriers are known to have a significantly higher risk of contralateral breast cancer and potentially a higher risk of ipsilateral recurrence thought to be a new primary breast cancer. ${ }^{2,3}$ Furthermore, in mutation carriers/high-risk women with remaining breast tissue regular surveillance, including imaging examinations, is still indicated, which is not the case after PM. Although there are no data available from cost-effectiveness analyses, it is plausible that PM might be more cost-effective than other preventive options in unaffected mutation carriers. Also, without underestimating the impact on quality of life and especially on the quality of the sexual relationship, it has been shown that distress levels in women opting for PM had significantly decreased after surgery, that most women are satisfied with their decision, and that they would choose the procedure again. ${ }^{4,5}$ It is possible that cultural differences may play a role in the decision-making process and at least partly explain the difference with respect to attitudes and choices hereby.

The comment of the authors that given the lack of difference in overall survival between BRCA1/2-associated and sporadic breast cancer, as reported in a recent study, the value of genetic testing as well as any prophylactic interventions is questionable is very surprising. First, a nonsignificantly different survival in BRCA1 and BRCA2 compared with sporadic breast cancer has also previously been reported by our and other groups and therefore is not a new observation. Second, and most important, most of the available survival data have been obtained from retrospective studies. The concrete goals of genetic testing and appropriate measures for identified mutation carriers are to identify these women and include them in surveillance programs enabling early detection and/or prevention of the occurrence of breast/ovarian cancer. It is our opinion that in this way lives can be saved, although data from prospective studies have to be awaited.

To overcome the challenges of the complex decisionmaking management of BRCA mutation carriers and of dealing with women who have a strong family history but tested negative for a BRCA mutation, the Ioannina University developed a comprehensive, decision-making algorithm. ${ }^{6}$ Comparing this algorithm with our guidelines, we noticed some striking differences. First, in the Netherlands proven noncarriers from a family with a BRCA mutation are not considered anymore to have a significantly increased risk of developing breast and/or ovarian cancer compared with the general population. Therefore, according to our institutional and national guidelines, increased surveillance, or any other preventive options, are not recommended for these women. ${ }^{7}$ Second, at our institute systematic testing for CHEK2 mutations has not been incorporated yet in the standard diagnostic genetic testing, as we previously reported incomplete cosegregation of the CHEK2 1100delC genotype with the breast cancer phenotype. ${ }^{8}$ This strategy is also used in other institutions in the Netherlands. Certainly, this may be reconsidered if further data become available, ${ }^{9}$ although incomplete cosegregation remains a problem to be solved.

The observations that routine practices at the moment still differ between the Netherlands and Greece is only emphasizing the importance of further studies into the subject to be carried out in order to obtain more evidencebased data with respect to both BRCA- and non-BRCAassociated breast cancer. This warrants joint efforts of national and international working groups.

Bernadette Heemskerk-Gerritsen Cecile Brekelmans, PhD, MD, and

Caroline Seynaeve, PhD, MD

Erasmus MC-Daniel den Hoed Cancer Centre Rotterdam, The Netherlands

e-mail: b.heemskerk-gerritsen@erasmusmc.nl 


\section{OPEN ACCESS}

This article is distributed under the terms of the Creative Commons Attribution Noncommercial License which permits any noncommercial use, distribution, and reproduction in any medium, provided the original author(s) and source are credited.

\section{REFERENCES}

1. Meijers-Heijboer H, van Geel B, van Putten WL, et al. Breast cancer after prophylactic bilateral mastectomy in women with a BRCA1 or BRCA2 mutation. N Engl J Med 2001; 345:159-64.

2. Pierce LJ, Levin AM, Rebbeck TR, et al. Ten-year multi-institutional results of breast-conserving surgery and radiotherapy in BRCA1/2-associated stage I/II breast cancer. J Clin Oncol 2006; 24:2437-43.

3. Haffty BG, Harrold E, Khan AJ, et al. Outcome of conservatively managed early-onset breast cancer by BRCA1/2 status. Lancet 2002; 359:1471-7.
4. Bresser PJ, Seynaeve C, Van Gool AR, et al. Satisfaction with prophylactic mastectomy and breast reconstruction in genetically predisposed women. Plast Reconstr Surg 2006; 117:167582.

5. Lodder LN, Frets PG, Trijsburg RW, et al. One year follow-up of women opting for presymptomatic testing for BRCA1 and BRCA2: emotional impact of the test outcome and decisions on risk management (surveillance or prophylactic surgery). Breast Cancer Res Treat 2002; 73:97-112.

6. Roukos DH, Briasoulis E. Individualized preventive and therapeutic management of hereditary breast ovarian cancer syndrome. Nat Clin Pract Oncol 2007; 4:578-90.

7. Tilanus-Linthorst MM. No screening yet after a negative test for the family mutation. J Med Genet 2007; 44:e79.

8. Meijers-Heijboer $\mathrm{H}$, Wijnen $\mathrm{J}$, Vasen $\mathrm{H}$, et al. The CHEK2 1100 delC mutation identifies families with a hereditary breast and colorectal cancer phenotype. Am J Hum Genet 2003; 72:1308-14.

9. Weischer M, Bojesen SE, Ellervik C, et al. CHEK2*1100delC genotyping for clinical assessment of breast cancer risk: metaanalyses of 26,000 patient cases and 27,000 controls. J Clin Oncol 2008; 26:542-8.

Published online April 9, 2008. DOI: $10.1245 / \mathrm{s} 10434-008-9878-1$ 